\title{
"You cannot take it with you": Reflections on intersectionality and social work
}

\author{
Eileen Joy, University of Auckland, New Zealand
}

\begin{abstract}
Intersectionality is a little explored topic in social work and this article seeks to address that gap with a particular focus on Aotearoa New Zealand. It begins with an examination of the genealogy of intersectionality through an acknowledgement that the concept has a longer lineage than the name. This foray into genealogy underscores the point that meticulous citational practice is a key component of good intersectional practice. Definitional challenges are briefly addressed, and the idea that theory and praxis are intimately connected is explored. Following this, intersectionality is discussed in the context of mana wahine, the author's own experiences, and recent developments in intersectionality in Aotearoa New Zealand. Finally, there is a discussion of why intersectionality is needed in social work with examples drawn from reflective practice and child protection in Aotearoa New Zealand.
\end{abstract}

KEYWORDS: intersectionality; mana wāhine; feminism; decolonisation; oppression

On reflection, I cannot recall the exact words that were used to tell me that I could not take the unopened (and thus uneaten) food back with me, but I remember my confusion, my anger, and feeling like I had lost control over a situation. I was one of the Women's Rights Officers at the University of Auckland many years ago, and I had just finished a women's hui, a noho that I and my fellow Women's Rights Officer had organised. I was in my very early 20s, a Pākehā woman, middle class, from the North Shore (a relatively affluent and largely Pākehā, middle-class area in Auckland), and I did not understand why the food we had brought to the meeting, into the wharekai next to the wharenui, food we had a very small budget for, could not be taken back and used for future women-focused events. I did not understand why the wāhine of the marae were telling me that what I wanted could not happen. I did not understand that the food I had brought now belonged to the marae and that it was rude of me to assume otherwise.

Decades have passed since that encounter, and now I look back on it with a suitable amount of embarrassment, and an acknowledgement that my knowledge of Te Ao Māori will always be limited (although, admittedly, not as limited as it was then). In a sense though, the idea that "you cannot take it with you" has remained with me. I can gain second-hand knowledge of what it is like to live as wahine Māori, I can even spend time on a marae (as I did) but it is not, in a sense, knowledge that I can take with me, I cannot live through that knowledge, that belongs specifically to wāhine Māori (see Murphy (2017) for a similar discussion). This one event in my life is one I have often called upon to help me to understand why I sometimes cannot immediately see power dynamics, and why other people might not be able to see the power dynamics that situate me. Drawing from Crenshaw (1989), I can be a bystander and observe the intersections where wāhine Māori stand, at the nexus of racism and sexism, but I cannot myself stand in the middle of that intersection. I myself have only lived experience of the cars coming from one direction in this particular intersection, 
I cannot know what it is like to face cars coming from both, but I must acknowledge that it exists. My own intersections are both varied and different, for example, living as a bisexual woman who is married to a male partner I sit in a particular intersection that my partner cannot ever occupy. This acknowledgement (and continued learning) of the situated self (Haraway, 1988) is what brings me here to sketch a brief outline of what intersectionality is (combined with a limited genealogy of the concept), how it relates to Aotearoa New Zealand, and critically, why an engagement with the concept in social work circles is long overdue.

\section{What is intersectionality?}

Intersectionality has been variously defined, with scholars noting some definitions (often those given by critics) are limited and/or do not pay attention to the genealogy of the concept (Cho, Crenshaw, \& McCall, 2013; Collins, 2015; May, 2015). Given the problems that some face in defining intersectionality, Collins and Chepp (2013) suggest that the following can be used as a "working definition":

Intersectionality consists of an assemblage of ideas and practices that maintain that gender, race, class, sexuality, age, ethnicity, ability, and similar phenomena cannot be analytically understood in isolation from one another; instead these constructs signal an intersecting constellation of power relationships that produce unequal material realities and distinctive social experiences for individuals and groups positioned within them. (p. 3)

Critically, it is important to note that intersectionality is not simply a matter of identities (a common criticism), rather it is how power creates identities and identities create (or deny) power (Collins, 2015; Collins \& Chepp, 2013). Equally important is the notion that intersectionality is not a completed project, instead it is a "knowledge project, or more accurately ... a constellation of knowledge projects." (Collins
\& Chepp, 2013, p. 4). This latter point is perhaps best understood by the rather paradoxical idea that it is a construct that deconstructs constructs (Collins \& Chepp, 2013). Put simply, referencing back to my own experiences, I sit on the intersections of being a Pākehā, bisexual, cisgender, educated woman, and this situates me differently in power relations depending on which identity(ies) I (or others) find to be most salient, or invisibilised (or anything in between) in any given moment. It also affords me the opportunity to create coalitions of support based on intersecting identities, coalitions which do not have to embrace every intersection, but can be mutually beneficial in particular instances. Collins and Bilge are clear that identity must be conceptualised as "inherently coalitional" (2016, p. 133) - as opposed to some critics of identity who focus on how it could divide - for only in seeing the similarities can we identity the inter- and intra-group power dynamics.

Intersectionality as an unnamed concept has been around for many decades, even centuries, before Kimberlé Crenshaw used the metaphor of a traffic intersection (Collins, 2015). As an idea, it has largely been advanced by the actions and thoughts of women of colour, and in more scholarly circles in recent times, African-American women have been at the forefront of both creating the maps and a cartography of intersectionality. Many scholars draw on the works of women like Sojourner Truth (who challenged US-based white women's definitions of womanhood in the 1840s), the Combahee River Collective (a group of Black lesbian socialists), and writings from African-American women in the time of slavery, to demonstrate that the idea that people can sit across multiple powered and disempowered identities has a rich, and often ignored, genealogy (Collins \& Bilge, 2016; May, 2015). Indeed, it has been suggested that it is a necessary intersectional practice to acknowledge the lineage of ideas; that meticulous citational practice is at the heart of ensuring the voices of multiple identities continues to be represented and is not silenced (Moradi \& Grzanka, 2017). May (2015) states 
that this commitment to citations "offer[s] a way to mark collectivity, delineate historical precedence, and claim legacies of struggle" (p. 55). In simple terms this does not mean a strict adherence to APA guidelines (for example), rather it means that those of us who do social work, in whatever capacity, must deeply interrogate our work to ensure that what we are presenting as ours is truly ours. It means actively honouring those who have spoken these ideas before us and speaking their names.

It is important to note that, as hinted at by referring to citational practices, intersectionality is more than theory, rather it is theory and praxis, the two intimately interwoven: theory-praxis. As has been stressed by many intersectionality scholars, intersectionality operates with a both/and approach rather than either/or (Collins, 2013; May, 2015). May (2015) admits that this is challenging; however, it is essential to allow multiple standpoints to exist simultaneously. Collins (2013) illustrates the importance of this when she explains that:

Either/or dichotomous thinking is especially troublesome when applied to theories of oppression because every individual must be classified as either oppressed or not oppressed. The both/ and position of simultaneously being oppressed and oppressor becomes conceptually impossible. (p. 216)

Thus Collins (2013) takes up the position of the intellectual activist meaning that the action of thinking, writing, and talking about intersectionality is activism - as valid as the activism of street protests and active lobbying, and vice versa. This collapsing of binaries between things that might traditionally be thought of as separate is important to note. The act of doing intersectionality becomes as much about the thinking as the doing; one cannot simply use the word 'intersectionality' without engaging in the doing of intersectionality, to do so is to miss the point - as well as ignore the important insights and intellectual contributions that people engaged in less traditionally scholarly jobs and activism are able to bring to the table.
In asking, "What is intersectionality?" a related question then is, "What is intersectional research?", or perhaps, "What counts as doing intersectional research?" Many authors helpfully provide guidelines on how to do intersectional research (Collins, 2015, p. 14; May, 2015, p. 229; Moradi \& Grzanka, 2017); however, given space prevents a more thorough examination of these guidelines I will briefly introduce the oft-cited McCall (2005) three-part framework. This framework suggests that, for research to be intersectionally informed, it is either: (1) anticategorical (deconstructs and questions all categories); (2) intercategorical (uses existing categories to show power differentials, whilst recognising their limitations - often used for studies between groups); or (3) intracategorical (sits somewhat between the other positions, does not completely use or reject categories, retains a critical view toward them, is often used in within group studies) (McCall, 2005; Murphy, Hamilton, Hunt, Norris, \& Zajicek, 2009).

Thus, we can observe, through discussing how intersectionality has been framed in the past and through research, that it is complex, and seems to resist easy definitions. Many scholars note this (see: Collins \& Bilge, 2016; May, 2015), with Collins (2015) noting that it cannot be defined too broadly or narrowly, and in fact we must be careful to observe what is and is not lost through iterations of intersectionality in places like academic institutions. Collins (2015) stresses that there cannot be a "finished definition" and that definitions "emerge from more iterative, grassroots processes ... everyday practices such as organizing sessions, developing syllabi, or choosing citations" (p. 3). This lack of complete definition might seem to make intersectionality tricky to grasp, however it is no different really from other schools of thinking that have, over time, developed, refined and even created different iterations. Where intersectionality may differ from many is that it tends to be more upfront about the iterative process than other discourses that may claim a more objective or rational stance. 


\section{Intersectionality in Aotearoa New Zealand}

It is not my intention, in this section, to provide a full overview of intersectionality in Aotearoa New Zealand, that sort of project is beyond the scope of this article. Instead, I present here a brief outline of the importance of understanding that intersectionality is not a recent academic import, as well as some examples of its more recent influence. Rather like intersectionality in the United States, and elsewhere, intersectionality as a concept had a long history in Aotearoa New Zealand before it was called intersectionality (Murphy, 2017). Murphy (2017) notes that the history of feminism, particularly white Western feminism, in Aotearoa New Zealand was preceded (and challenged) by mana wāhine. Drawing on Ngahuia Te Awekotuku (1991), Murphy (2017) notes that "in Aotearoa, the shattering of Māori through colonisation remains at the forefront of any intersectional feminist consciousness and is informed by our own commitment to Te Tiriti o Waitangi and tino rangatiratanga" (p. 6). Through recourse to discussions of mana wāhine by women such as Leonie Pihama, Kathy Irwin, and Linda Tuhiwai Smith, Simmonds (2011) explains that mana wāhine is "an extension of Kaupapa Māori" (p. 13) and is a "space where Māori women can, on our own terms and in our own way, (re) define and (re)present the multifarious stories and experiences of what it means, and what it meant in the past, to be a Māori woman in Aotearoa New Zealand" (pp. 11-12). It is important to note that the term intersectionality itself does not replace mana wāhine, intersectionality is not a Māori concept, rather, there are coalitional opportunities and alignments; further, as Murphy (2017) notes, any intersectional stance in Aotearoa New Zealand must incorporate decolonisation. Thus interrogating power and identity, as intersectionality does, cannot be considered to be a recent academic import; such a notion silences and colonises wāhine Māori, not to mention the experiences of other women of colour and members of marginalised communities who live and have lived in Aotearoa New Zealand.

For myself intersectionality in Aotearoa New Zealand means that as a Pākehā I have to explicitly take up a position to encompass anti-racist work (encompassing decolonisation) and I have to be prepared to be told that "you cannot take it with you" on a daily basis. More generally it means, for example, that I interrogate my work as a social worker, as a person, and as a parent, to ensure, as much as possible, that I am not trying to take something with me that does not belong to me. As a bisexual woman who has a male partner it means that my own identity is often silenced within the larger rainbow community in Aotearoa New Zealand and this informs my work within the community to ensure that bisexual voices are not lost (Joy, 2018). It means continually mapping out my identity at a personal and a societal level to see where my identity is constructed as power giving and where it is not; this is work that is lifelong and rarely easy.

Certainly, explicitly (and not so explicitly) named intersectionality theory and praxis in Aotearoa New Zealand is on the rise. Schuster (2016) observes, that young feminist women in Aotearoa New Zealand are using intersectionality more than older women, with both Pākehā and Māori women using the concept to describe how they reflect on privilege (their own and others') as a way to ensure that different identities are heard and not erased. Intersectionality has also started entering the mainstream media as a talking and action point. For example, a commitment to intersectionality was cited as one reason for not allowing the police in Aotearoa New Zealand to wear their uniforms in the annual Auckland Pride parade (Auckland Pride Board, 2018); it has been used to explain the necessity of including trans women in a Suffrage celebration exhibition (Clark, 2018); and was referenced in reflecting on the privilege of being an "old straight white guy" (Shimmin, 
2018) in a small community South Island newspaper.

\section{Why we need intersectionality in social work}

Given the genealogy of intersectionality, both internationally and nationally, and that it is currently being used as both theory and praxis as a way to grapple with issues of oppression and power, this would seem to make it a logical fit for social work and social workers. There has been limited writing on the overall integration and/or alignment of social work and intersectionality (see as examples: Mattsson, 2014; Mehrotra, 2010; Murphy et al., 2009; Nayak \& Robbins, 2019) and, to my knowledge, there has been no specific writing on this in Aotearoa New Zealand. The rich and equally troubled history of social work in working within power structures and for (and often against) members of marginalized communities is a useful starting point to considering why social work, and social workers themselves would benefit from an alignment with, and use of, intersectionality theory and practice. We have to consider what we can and cannot "take with us" when we meet with clients, conduct research, when we think about our work. An understanding of intersectionality for example, could help to explain how child protection social work in Aotearoa New Zealand can move beyond racist practices (both historical and present) such as the tokenistic use of the Māori language (Moyle \& Tauri, 2016). Such examination could assist child protection social workers and policy makers to confront and address arguably racist practice that continues to see Māori whanau as somehow "riskier" than equivalent Pākehā families (Keddell \& Hyslop, 2019).

However, intersectionality is more than just referring to one aspect of a person's identity. Referring to the concept of human rights as being key to social work, Murphy and colleagues (2009) assert that intersectionality allows us to not just see the separate identities of things like race and gender, rather it encourages us to understand how they interact. In the aforementioned example of racism in child protection, this can mean understanding how Māori women parents are specifically positioned (see: Ware, Breheny, \& Forster (2017), for an example of this). Murphy and colleagues (2009) go on to explain that such understanding is vital, not just for an understanding of clients (and populations), but critically for selfunderstanding. The criticality of this last point is further explored by Mattsson (2014) who suggests that current reflective practice, even that using critical reflection and antioppressive principles, is insufficient, and that using intersectionality may deepen self-reflection. Mattsson (2014) argues that critical reflection on its own can lead to a sort of relativism when the specific oppressions and power structures unique to race, gender, class, and sexuality (and their interactions) are not carefully and specifically considered. However, Murphy and colleagues (2009) warn that, for social workers, this sort of reflection could be extremely challenging and notes that "the thought for any social worker that, however intentionally, he or she is part of the greater system of oppression is, at the very least, an uncomfortable one. This process of self-examination can be painful" (p. 46).

The afore-mentioned self-examination should not, and I would argue cannot, be limited to social workers themselves. Applying Collins' (2013) call for "intellectual activism" and applying the "both/and" framework, such analysis must be extended beyond the self and clients to how we work within the macro, or perhaps even against the macro. This means considering how social work education, research, policy and practice would benefit from using intersectionality as theorypraxis. As an example, Nayak, Montenegro, and Pujol (2019) note that the way social services are split up, by age, family, marital status, sets up dividing practices which do not help people in contextualised situations. Such division of services forces people to highlight one identity at the expense of another (or others), and fails to consider 
that, for most people, such self-partitioning is not possible nor helpful. Awareness of the overlap and the indivisibility of identities and power structures should not mean a swing to the extreme of a one-size-fits-all approach, rather it means, at a basic level, helping the whole person and the whole community. This awareness of overlap and indivisibility should help generate social work education, research, practice and policy that refuses to silo matters such as ethnicity and gender (to name two such examples) into stand-alone issues.

For social work education this presents a unique challenge, rather than the habit of creating topic silos where one covers off topics like colonisation, the rainbow community, aged persons, in a course, or a few lectures or seminars, social work educators could rise to the challenge of breaking down the boundaries. Such breaking down of boundaries would mean considering each topic and asking, for instance, what this topic means for decolonisation; how this relates to a young takātapui person, an older refugee woman; how a middle-class Pākehā male is situated in this topic; and critically, how might I, as a uniquely situated social worker, respond to my own oppressions and privileges with regard to this topic. In undertaking such discourse, educators would be wise to consider not framing such conversations in a way that others marginalised groups and puts them(us) under an intense gaze. Rather, intersectionality can and should also consider how intersecting privileges compound and align to create certain opportunities and power structures. Asking questions such as what these topics mean for those whose identities grant them access to more power is as important as considering how specific identities are disenfranchised. It is through these latter questions, those that shift the gaze back to enfranchised identities, that the discomfort that Mattsson (2014) mentions, in recognising one's own place in the power structures as a social worker with specific identities, can be addressed.

\section{Concluding thoughts}

Intersectionality as a theory-praxis has a lot to offer social work in practice, education, research and policy. In embracing the both/ and position it is possible for those who do social work to align their practice with the goals and theory of intersectionality. We can learn to accept our situatedness in specific intersections, learn that we cannot take things with us, and that that knowledge does not limit us, rather it strengthens. Collins (2013) notes that:

Each group starts from its own standpoint and shares its own partial, situated knowledge. Yet, because each group perceives its own truth as partial, its knowledge is unfinished. Each group becomes better able to consider other groups' experiences without relinquishing the uniqueness of its own or suppressing other groups' partial perspectives. (p. 136)

Collins' challenge is therefore about acknowledging how power constructs specific identities and what we can gain from that recognition, how we might build coalitions through highlighting difference. We can have collective and individual identities, we do not have to choose, or prioritise, it is possible for one to not erase the other, for us to have both/and. If social work is to truly address things like human rights, oppression and social justice, then we have to accept that we cannot simply take things with us, that the deepest and most essential work can come from leaving things where they are and accepting you have no place in that specific intersection other than to sit on the side, listen and provide amplifying opportunities for those who sit where you do not.

\section{Glossary}

Kaupapa Māori: A specifically Māori approach to doing things, in research referred to as Māori researchers doing research with Māori about Māori. 
Mana wāhine: Looking at things through being a Māori woman, often considered to be Māori feminism.

Marae: The meeting area in front of the wharenui, can also be used to describe all the buildings around it.

Noho: An overnight stay.

Pākehā: The name given to the British colonists to Aotearoa, in modern times usually used to refer to New Zealanders of European descent who are white skinned. Takātapui: Any Māori person who is lesbian, gay, bisexual, trans, intersex.

Te Ao Māori: Māori world view.

Tino rangatiratanga: Self-determination and governance, in this instance referring to the right in the Māori version of the Treaty of Waitangi for Māori people to govern their own affairs.

Wahine: Woman.

Wāhine: Women.

Whanau: Family.

Wharekai: Kitchen or dining hall.

Wharenui: Meeting house located on a marae.

\section{References}

Auckland Pride Board. (2018, November). Auckland Pride Board confirms position on police uniforms in parade. Retrieved from https://aucklandpride.org.nz/mediacentre/auckland-pride-board-confirms-position-on-policeuniforms-in-parade/

Cho, S., Crenshaw, K. W., \& McCall, L. (2013). Toward a field of intersectionality studies: Theory, applications, and praxis. Signs: Journal of Women in Culture and Society, 38(4), 785-810.

Clark, J. (2018, July 23). Equality, presupposes that we should all be equal, but in fact, none of us really ever are. Manukau Courier. Retrieved from https://www.stuff. co.nz/auckland/local-news/manukau-courier/105673174/ jackie-clark-equality-presupposes-that-we-should-all-beequal-but-in-fact-none-of-us-really-ever-are

Collins, P. H. (2013). On intellectual activism. Philadelphia, PA: Temple University Press.

Collins, P. H. (2015). Intersectionality's definitional dilemmas. Annual Review of Sociology, 41(1), 1-20.

Collins, P. H., \& Bilge, S. (2016). Intersectionality. Cambridge, United Kingdom: Polity Press.

Collins, P. H., \& Chepp, V. (2013). Intersectionality. In G Waylen, K. Celis, J. Kantola, \& S. L. Weldon (Eds.), The Oxford handbook of gender and politics (pp. 1-34). Oxford, United Kingdom: Oxford University Press.

Crenshaw, K. (1989). Demarginalizing the intersection of race and sex: A black feminist critique of antidiscrimination doctrine, feminist theory and antiracist politics. University of Chicago Legal Forum, 1989(1), 139-167.

Haraway, D. (1988). Situated knowledges: The science question in feminism and the privilege of partial perspective. Feminist Studies, 14(3), 575-599.
Joy, E. (2018, February 19). Why social work needs Pride [Web log post]. Retrieved from http://www. reimaginingsocialwork.nz/2018/02/why-social-workneeds-pride/

Keddell, E., \& Hyslop, I. (2019). Ethnic inequalities in child welfare: The role of practitioner risk perceptions. Child \& Family Social Work. https://doi.org/10.1111/cfs.12620

Mattsson, T. (2014). Intersectionality as a useful tool: Anti-oppressive social work and critical reflection. Affilia, 29(1), 8-17.

May, V. M. (2015). Pursuing intersectionality, unsettling dominant imaginaries. New York, NY: Routledge.

McCall, L. (2005). The complexity of intersectionality. Signs: Journal of Women in Culture and Society, 30(3), 1771-1800.

Mehrotra, G. (2010). Toward a continuum of intersectionality theorizing for feminist social work scholarship. Affilia, 25(4), 417-430.

Moradi, B., \& Grzanka, P. R. (2017). Using intersectionality responsibly: Toward critical epistemology, structural analysis, and social justice activism. Journal of Counseling Psychology, 64(5), 500-513.

Moyle, P., \& Tauri, J. M. (2016). Māori, family group conferencing and the mystifications of restorative justice. Victims \& Offenders, 11(1), 87-106.

Murphy, L. (2017). Intersectional feminisms: Reflections on theory and activism in Sara Ahmed's living a feminist life (2017). Women's Studies Journal, 31(2), 4-17.

Murphy, Y., Hamilton, L., Hunt, V. H., Norris, A. N., \& Zajicek, A. M. (2009). Incorporating intersectionality in social work practice, research, policy, and education. Washington DC, United States: NASW Press, National Association of Social Workers.

Nayak, S., Montenegro, M., \& Pujol, J. (2019). Conclusion: Contextual intersectionality: A conversation. In S. Nayak \& R. Robbins (Eds.), Intersectionality in social work: Activism and practice in context (pp. 230-250). Abingdon, United Kingdom: Routledge.

Nayak S., \& Robbins R. (2019). Intersectionality in social work: Activism and practice in context. New York, NY: Routledge.

Schuster, J. (2016). Intersectional expectations: Young feminists' perceived failure at dealing with differences and their retreat to individualism. Women's Studies International Forum, 58, 1-8.

Shimmin, G. (2018, December 7). Appreciating the value of shutting up and listening. Timaru Herald. Retrieved from https://www.stuff.co.nz/timaru-herald/opinion/109178573/ appreciating-the-value-of-shutting-up-and-listening

Simmonds, N. (2011). Mana wahine: Decolonising politics. Women's Studies Journal, 25(2), 11-25.

Te Awekotuku, N. (1991). Mana wahine Māori: Selected writings on Māori women's art, culture and politics. Auckland, New Zealand: New Women's Press.

Ware, F., Breheny, M., \& Forster, M. E. (2017). Reproducing the precarious position of young Māori mothers in Aotearoa New Zealand. In S. Groot, N. Tassell-Matamua, C. Van Ommen, \& B. MastersAwatere (Eds.), Precarity: Uncertain, insecure and unequal lives in Aotearoa New Zealand (pp. 136-146). Palmerston North, New Zealand: Massey University Press. 